\title{
EVALUATION OF VORTEX FLOW CONTROLS EFFICIENCY BASED ON CFD NUMERICAL MODELLING
}

\author{
Tomasz Siuta ${ }^{凶}$, Andrzej Mączałowski \\ Faculty of Environmental and Power Engineering, Cracow University of Technology, Warszawska 24, 31-155 Krakow
}

\begin{abstract}
Aim of the study

Aim of the paper was to map the bistable characteristics of vortex flow controls (VFCs) and to indicate optimal geometry parameters of the tested ones, such as: chamber diameter, inlet and outlet orifice area for set project conditions. In addition, the method for assessing the range of effective use of VFCs was verified on the base of the so-called swirl parameter in regard to the obtained numerical modelling results.
\end{abstract}

\begin{abstract}
Materials and methods
During the research, numerical modelling (CFD) determined the flow set by a tested VFCs for a given disposable pressure head. Series of calculation were run for three variants of the VFCs geometry. Numerical solution of the flow model equations of single-phase non-compressible liquid (Reynolds Averaged Navier-Stokes) together with the closing equations of the k- $\varepsilon$ turbulence model were made in the FLOW 3D computer program.
\end{abstract}

\section{Results and conclusions}

Obtained characteristics of the VFCs expenditure based on numerical calculations are bistable (two-branch process separated by an unstable zone), which was previously confirmed in laboratory experiments carried out in different research. The method for assessing the scope of effective operation of vortex flow controls devices based on the so-called swirl parameter was positively verified in the light of the results of numerical modelling, which allows for optimal dimensioning of VFCs and their proper selection for specific operating conditions.

Keywords: sewage system, vortex flow controls, bistable characteristics, swirl parameter, CFD numerical model

\section{INTRODUCTION}

Vortex flow controls are used for passive control of outflow from drains, distribution chambers and retention reservoirs in order to increase the efficiency of rainwater retention systems and combined sewage systems in conditions of intensive runoff from an urbanized catchment. Inefficient usage of retention in sewage systems in the upper part of catchment during intensive precipitation can lead to system failure and, consequently, flooding the lower part of the catchment (e.g. Wadley Road-London). In such case, VFCs can be installed in connection and distribution drains (equipped with e.g. storm spillway). In addition, these devices can also be used in chambers with separators, where part of the retained rainwater is held for initial treatment before it reaches the treatment plant. Another interesting application of a VFC, on a much larger

घe-mail: tomasz.siuta@iigw.pk.edu.pl 
scale (inlet diameter is about $1.7 \mathrm{~m}$ ), can be found in Weedon Bec in England, where it operates as a drain device installed on an earth-fill dam (Faram et al., 2010). A reservoir above this dam performs flood control functions (so-called dry reservoir). This significantly reduces a floodplain area, when compared to an area that would be needed with conventional uncontrolled bedding drainage during floods with a smaller inflow volume than that for which the reservoir was designed.

There are two ways to approach optimal geometry of VFCs. The first involves determining the dimensions of an outlet and the geometry of chamber to reach the largest possible decrease in energy after exceeding a certain flow rate, thus ensuring the most evenly distributed outflow rate (Wojtowicz and Kotowski, 2009). The second, used in the Anglo-Saxon countries, includes maximizing the outflow (capacity) during an average flood, while ensuring that the maximum outflow for which the reservoir or sewage chamber is designed is not exceeded (Jarman et al., 2015). Both these approaches are not mutually ex- clusive and can sometimes lead to different optimal measures with the same construction restrictions depending on the function that VFC are to perform in a sewage system.

\section{PRINCIPLE OF VORTEX FLOW CONTROLS OPERATION}

The geometry of VFCs is described by a cylindrical or conical shape of a chamber, in which an inlet is located in tangent direction to a perimeter of the chamber and an axial outlet located perpendicularly to the chamber (see: Fig. 1). Such location of an inlet forces vortex flow in the chamber, provided that sufficient inlet pressure is achieved. There are two ways to install a VFC: the first - axis of the outlet stub end is directed horizontally, the second - outlet axis is directed vertically. The second is rarely used, but doubtless it has an advantage of better treatment in reservoirs with wastewater from combined sewage system (Kotowski and Wojtowicz, 2008). The controlers operates in three modes. The first works at low flow rates. Hydraulic character-
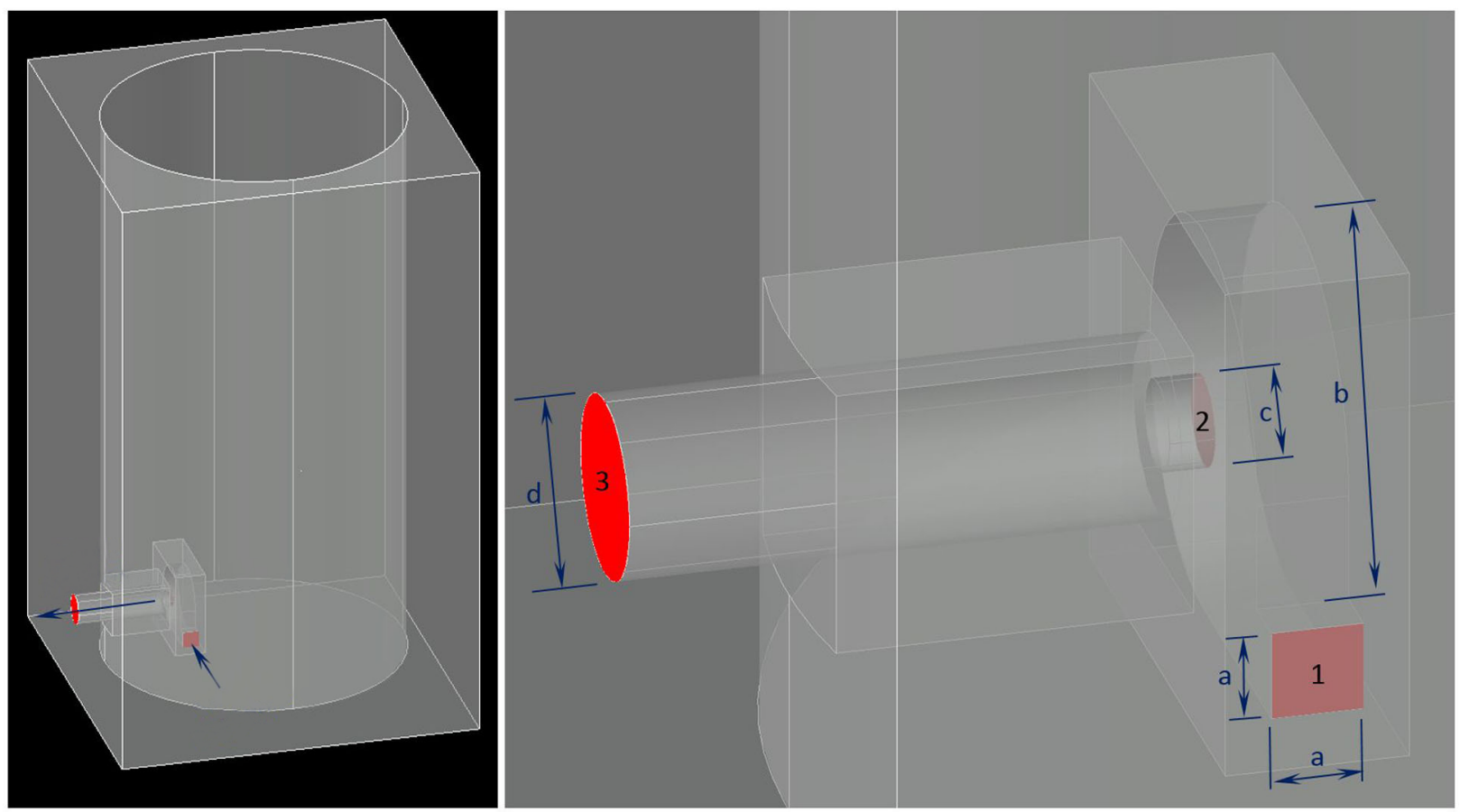

1 - inlet surface of the VFC; 2 - surface of the outlet from the cylindrical chamber; 3 - cross-sectional area of the stub end connector

Fig. 1. Vortex flow control and its location in the drain 
istics of the device are similar to those of a thin-walled splilway (Queguineur, 2013), when a chamber is not completely filled. The second serves as an unstable transition phase, when vortex motion begins to form and air remains in the chamber core (Jarman et al., 2015). The third mode proceeds exceeding a boundary flow after a full vortex motion develops. The device's capacity is rapidly reduced and the VFC's flow curve characteristics change (see: Fig. 2).

The reason for the reduction of capacity in this case is a high loss of disposable pressure caused by inertial forces and dissipation of some turbulent energy. The described above dynamic variability of a VFC is referred to as bistable (Jarman et al., 2015).

\section{PURPOSE AND DESCRIPTION OF THE NUMERICAL EXPERIMENT}

Research papers on vortex flow controls present results of experimental tests on various aspects of VFC, such as: assessment of impact of geometric and dynamic parameters on effective control of outflow, verification of optimal chamber shape (cylindrical or conical), assessment and significance of spatial orientation of the outlet stub end, and its sinking (Kubrak et al., 2015). In effect, numerous empirical formulas put forward in these works provide guidance for designing of these devices (Parsian, 1993), (Kotowski and Wojtowicz, 2008). Numerical modelling is also becoming a valuable addition to empirical formulas, which, after prior verification based on experimental data, can facilitate designing of device prototypes, as well as help to understand better the hydrodynamic processes associated with inertial vortex flows. The authors' primarily attempted to outline the complex (bistable) nature of an exemplary vortex controler through a numerical simulation using the CFD (Computational Fluid Dynamics) method. A further aim was to choose an optimal geometry of the VFC that met the set design conditions. A series of calculations was run for three tested variants of the VFC geometry for flow rate in the range from $0.2 \mathrm{dm}^{3} \cdot \mathrm{s}^{-1}$ to $3 \mathrm{dm}^{3} \cdot \mathrm{s}^{-1}$ depending on the of disposable pressure head. The course of numerical experiment included changing the difference in height of the ordinate above the VFC inlet and calculating its expenditure, with the outlet stub end being treated for each calculation as a or- ifice submerged up to the height of its upper edge. The range of the mentioned difference in pressure height determined for the tested calculations varies from $0.5 \mathrm{~cm}$ to $240 \mathrm{~cm}$. Reports from similar studies, although with an emphasis on verifying the compliance of CFD simulations with laboratory experiments results, have already been described in Jarman et al. 2015. In this case, the VFCs designed for larger flow rates (from $4 \mathrm{dm}^{3} \cdot \mathrm{s}^{-1}$ to $8 \mathrm{dm}^{3} \cdot \mathrm{s}^{-1}$ ) were tested under quasi-steady flow conditions. In regard to small drains (designed for a maximum flow below $2 \mathrm{dm}^{3} \cdot \mathrm{s}^{-1}$ ), increasingly applied to sewage systems in Poland, testing VFCs with lower capacity provides valuable supplement to the existing knowledge on this subject.

As the results of research on the optimal design of VFCs show (Gupta, 1984), the main factor determining their effectiveness is swirl parameter (Eq. 1).

$$
S_{g}=\frac{\pi D_{k} D_{w y}}{4 A_{w l}}
$$

given:

$D_{c h}-\mathrm{m}$, diameter of VFC of the chamber,

$D_{o}-\mathrm{m}$, diameter of outlet from the chamber,

$A_{i}-\mathrm{m}^{2}$, chamber inlet area.

Swirl parameter can be physically interpreted by a monotonic functional relationship with a dimensionless vortex number. This number determines the ratio of angular momentum flux of rotating liquid mass to the product of angular flux (calculated in the axial direction, perpendicular to vortex) and vortex radius (Gupta, 1984). From the point of view of VFC's effective operation, the upward tendency of swirl parameter along with the increase in the so-called Euler numbers (equals 2) is significant. This number expresses the ratio of pressure drop in liquid volume element due to the loss of potential energy and its partial conversion into kinetic energy.

$$
E u=\frac{4 \Delta p}{\rho u_{s r}^{2}}
$$

given:

$\Delta p-\mathrm{Pa}$, drop in disposable pressure in outlet cross-section,

$u_{\text {avr }}-\mathrm{m} / \mathrm{s}$, average flow velocity. 
The Euler number can be understood here in the context of loss of pressure head caused by strongly turbulent vortex flow in the VFC, at a set value of outflow rate. The analysis of functional relationship of the Euler number to swirl parameter (closely related to the VFC's geometry) allows determining its optimal value, and thus the optimal geometry of VFC, for specific conditions of maximum design outflow rate. For practical reasons (long time-span of calculations), the spatial range of the numerical model was limited to the geometric extent of the VFC, increased by a fragment of drain volume (cylinder with a diameter of $1 \mathrm{~m}$ ). The assumed range of the spatial domain provided mapping of velocity magnitude increase in the vicinity of the inlet to the VFC chamber (see: Fig. 7). Based on a number of simulations, the changes in outflow rate from the VFC were tested depending on the assumed constant level of water table in the drain.

\section{DESCRIPTION OF THE GEOMETRY OF TESTED VFCS DEVICES}

In this paper, the tested models differ only in size of the cylindrical chamber diameter (dimension $b$ in Fig. 1), which value - depending on model - is: $20 \mathrm{~cm}$ (VFC: $d 20), 30 \mathrm{~cm}$ (VFC: d30), $40 \mathrm{~cm}$ (VFC: $d 40$ ). Other dimensions are the same in all cases: $50 \mathrm{~mm}-$ the length of the side of the inlet with a square surface area of the slot (dimension $a$ in Fig. 1), $50 \mathrm{~mm}$ - the diameter of outlet from the chamber (dimension $c$ in Fig. 1), $100 \mathrm{~mm}$ - the internal diameter of the stub end draining water outside (dimension $d$ in Fig. 1). The internal width of the chamber is equal to the width of the inlet and is $50 \mathrm{~mm}$.

\section{MATHEMATICAL MODEL AND ITS NUMERICAL REPRESENTATION}

The Navier-Stokes model was applied for mathematical description of the complex three-dimensional dynamics of flow through a VFC. For simplification, it was adopted that the flow is single-phase and the fluid incompressible. In fact, as reported by previous studies (Jarman et al., 2015), in conditions of vortex flow, air enters through the VFC's outlet orifice, which lies separated in the chamber just above the outlet. However, the same research shows that practical sig- nificance of this process (i.e. the impact on device's operation) is small and disappears with larger outflow rates, when we observe a fully developed vortex flow in the VFC chamber. Due to the expected significance of turbulent effects accompanying vortex flow, it becomes necessary to include turbulent Reynolds stress (in the form of the so-called RANS model) in the mathematical model. Reynolds stress has been formulated in the form of Boussinesq equation (Eq. 3). In this paper, the RANS model equations have been supplemented with the turbulence model $k-\varepsilon$, which indirectly - by determining parameters such as turbulent energy rate $(k)$ and energy dissipation rate $(\varepsilon)$ - allows calculating turbulent viscosity parameter (Eq. 4), and thus determining the Reynolds stress tensor. The selection of the appropriate turbulence model should be accordant with verification of the numerical model based on experimental results. However, due to lack of appropriate measurement data this was not the aim of this research. The results of previous studies (Jarman et al., 2015) show that, in fact, it is possible to improve significantly the compliance of numerical simulations with experimental results by using the SMT (Second Moment Turbulent) model, but at the expense of extending notably the simulation time and of numerical complications that generally occur in methods of direct calculation of turbulent stress tensor components.

$$
\begin{gathered}
\tau_{R i j}=v_{t}\left[\frac{\partial u_{i}}{\partial x_{j}}+\frac{\partial u_{j}}{\partial x_{i}}\right]-\frac{2}{3} \delta_{i j} k \\
v_{t}=0.9 \frac{k^{2}}{\varepsilon}
\end{gathered}
$$

given:

$u_{\mathrm{and}}-\mathrm{m} / \mathrm{s}$, components of velocity vector $i=1,2,3$,

$v_{t}-\mathrm{N} \cdot \mathrm{s} / \mathrm{m}^{2}$, turbulent viscosity,

$k-\mathrm{J} / \mathrm{kg}$, turbulent energy rate,

$\varepsilon \quad-\mathrm{J} /(\mathrm{kg} \cdot \mathrm{s})$, turbulent energy dissipation rate,

$\tau_{R i j}-\mathrm{N} / \mathrm{m}^{2}$, Reynolds stress tensor.

\section{FLOW 3D PROGRAM}

The FLOW 3D program (Flow Science, 2014) was used for presented calculations. It allows solving the RANS model equations (Eq. 5) adapted to the FAVOR 
technique (Flow Science, 2014) by additional variables. This is based on the control volume approach using the so-called staggered grid. A regular discretisation grid is generated in the program, therefore the FAVOR (Fluid Area and Volume Object Resolution) technique was employed for correct mapping of surfaces on the border of two phases (e.g. water-air), as well as mapping of flow parameters (mainly velocity and pressure) near the geometric boundary of a physical object model (here: vortex flow control devices).

The program generated a discretisation grid, including the geometric representation of the VFC together with the outlet stub end (see: Fig. 1) and the surrounding space inside the drain's fragment (the area in which there is a significant increase in velocity in the vicinity of the VFC inlet). The grid was constructed of regular cubic parts in three versions depending on the side length: $5 \mathrm{~mm}, 2.5 \mathrm{~mm}, 1 \mathrm{~mm}$. Then, the impact of the grid element size on the values of the calculated flow rate from the VFC and the change in its characteristics course were tested (see: Fig. 2). For grid size of $5 \mathrm{~mm}$ the simulation results do not reflect the actual bistable nature of the VFC, a reduction of grid size to $2.5 \mathrm{~mm}$ allows to capture the above-mentioned property, and further size reduction (to $1 \mathrm{~mm}$ ) does not introduce significant corrections, but significantly increases calculation time (the time for calculations on a computer with an Intel Core I7 CPU950 $3.07 \mathrm{GHz}$ dual-core processor of one simulation runs up to 12 hours).

$$
\begin{gathered}
\nabla \circ\left(\mathbf{u} \mathbf{A}_{\mathbf{f}}\right)=0 \\
\frac{\partial \mathbf{u}}{\partial t}+\frac{1}{V_{f}}\left(\mathbf{u A}_{\mathbf{f}} \circ \nabla\right) \mathbf{u}=-\frac{1}{\rho} \nabla P+\mathbf{G}+\mathbf{f} \\
\frac{\partial F}{\partial t}+\frac{F}{V_{f}} \nabla \circ\left(\mathbf{u} \mathbf{A}_{\mathbf{f}}\right)=0
\end{gathered}
$$

given:
u $-\mathrm{m} \cdot \mathrm{s}^{-1}$, velocity vector,
f $-\mathrm{m} \cdot \mathrm{s}^{-2}$, unit power viscosity vector,
$P-\mathrm{Pa}$, pressure,
$\mathbf{G}-\mathrm{m} \cdot \mathrm{s}^{-2}$, acceleration vector,
$V_{f}-\mathrm{m}^{3}$, volume fraction,
$\mathbf{A}_{\mathrm{f}}-\mathrm{m}^{2}$, surface fraction vector,
$F$ - dimensionless fraction of fluid.

\section{BOUNDARY CONDITIONS AND NUMERICAL PARAMETERS}

The upper boundary condition is a constant pressure head, corresponding to constant ordinate of water table in the drain with installed VFC (this approach significantly reduces calculation time compared to conditions of constant inflow rate). The downstream boundary condition is the piezometric zero pressure at the level of the upper edge of the outlet stub end connecting the VFC with the drain outlet (see: Fig. 1).

In the tested range of flow rates, for the assumed VFC geometry, the value of Reynolds number is of the order of $10^{4}$, thus the wall layer is a turbulent layer and velocity distribution is subject to the so-called logarithmic function of wall layer (Jarman et al., 2015). In order to correctly reproduce the effects related to boundary wall layer, the size of the discretising grid element adjacent to the wall, the selection of VFC should be determined by the dimensionless width of boundary layer $(y+)$ staying within range: $30<y+$ $<400$. In the case of tested discretisation grid with a linear size equal to $2.5 \mathrm{~mm}$, this condition is met because the calculated value $y+$ is between 160 and 300 for all tested VFC geometries. It was assumed that surface roughness coefficient of the VFC and the outlet stub end $(k)$ is of the order of $10^{-5} \mathrm{~m}$, and this value corresponds to smooth sheet metal usually used for producing these devices. Numerical calculations were run with a variable time step (the minimum value was $\Delta \mathrm{t}=10^{-4} \mathrm{~s}$ ), automatically adjusted by the program based on the adopted convergence criterion, until steady flow conditions were obtained. It took less than $10 \mathrm{~s}$ to achieve steady flow in all examined models. Numerical method was adopted as explicit with approximation accuracy of second order for advection terms.

\section{ANALYSIS OF CALCULATION RESULTS}

The characteristics course of the studied variants of VFC geometry is presented in Fig. 3. For all analysed variants of the VFCs, bistable nature was obtained $\mathrm{Q}(\mathrm{H})$, while in the case of variant $d 20$ the instability zone is the most noticeable (the same flow with a value of $0.9 \mathrm{dm}$ intensity ${ }^{3} \cdot \mathrm{s}^{-1}$ appears at different pressure heights $-0.2 \mathrm{~m}$ and $0.4 \mathrm{~m}$ ). As for the rest, the 


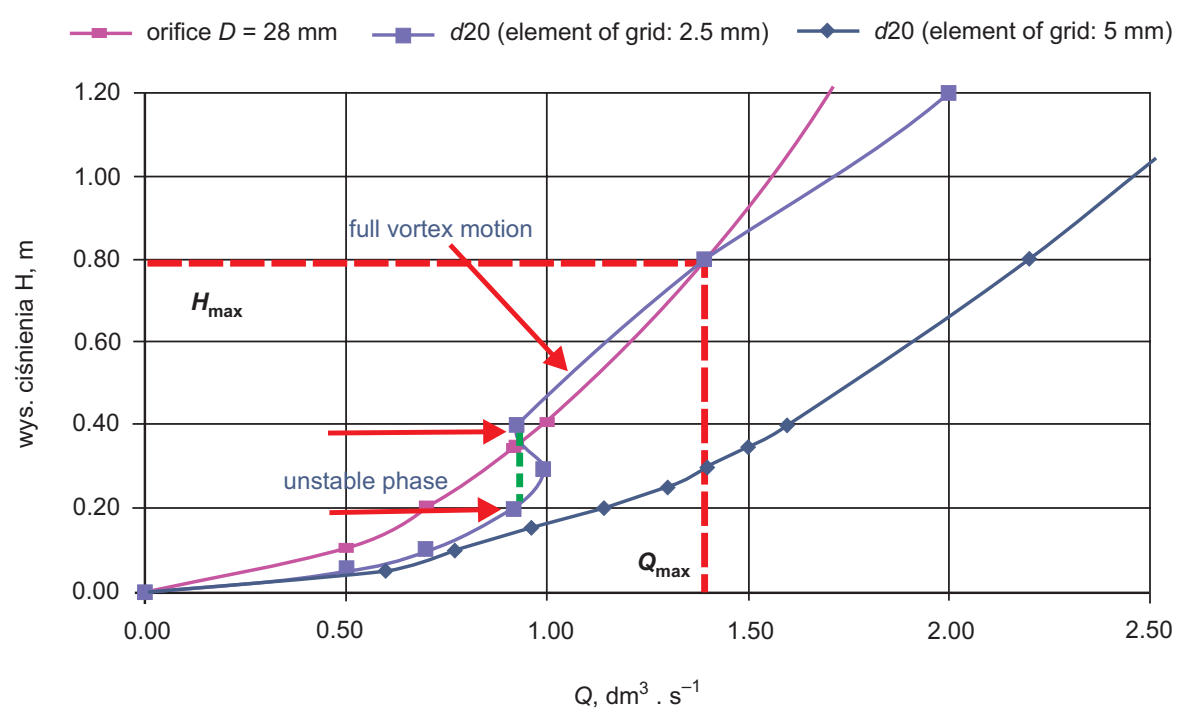

Fig. 2. The impact of the element of grid size changes in the VFC $d 20$ bistable characteristics performance and an example of equivalent orifice characteristics $(\mathrm{D}=28 \mathrm{~mm})$

transition is smoother and retains axioms of functional relationship.

The two-branch expenditure curve is characterized by a certain threshold value of outflow rate $\left(Q_{g r}\right)$ and an unstable outflow range with the width $\Delta Q_{\mathrm{gr}}$. For flows greater than $Q_{g r}+\Delta Q_{g r}$, the VFC's flow curve is a result of a fully developed vortex motion in its chamber. Based on the characteristics course (see: Fig. 3), it can be claimed that for all tested VFC variants: $Q_{g r} \approx 1 \mathrm{dm}^{3} \cdot \mathrm{s}^{-1}$. The VFCs' effectiveness can be evaluated by the maximum rise in pressure height (the largest energy losses) if an outflow rate exceeds the boundary rate $\left(Q_{g r} \approx 1 \mathrm{dm}^{3} \cdot \mathrm{s}^{-1}\right)$. According to this criterion, the VFC $d 20$ is the most optimal (pressure height is the highest at exceeding flow rate $Q_{g r}$ ), which follows the characteristics course (see: Fig. 3). Due to the fact that outflow VFCs are most often closely connected to retention functions of sewage systems, it is also necessary to compare the tested variants of VFC geometry in relation to equivalent thin-walled orifices. Knowing the maximum outflow rate $\left(Q_{\max }\right)$ at a given pressure $\left(H_{\max }\right)$, for which the VFC is designed, allows calculating the equivalent orifice diameter - its characteristics intersect with the characteristics of the VFC at the highest operating point (see: Fig. 3). Assuming, for example, $Q_{\max }=1.5 \mathrm{dm}^{3} \cdot \mathrm{s}^{-1}$, the equivalent orifice diameter for the VFC $d 30$ is $26 \mathrm{~mm}$, and for the VFC $d 40$ is $30 \mathrm{~mm}$. Comparison of the VFC characteristics course with the equivalent orifice characteristics allows to assess the extent to which VFC capacity (flow rate for a given pressure) is greater than orifice capacity for flow rates lower than $Q_{\max }$. For such criterion, the variant $d 30$ is optimal for flow $Q_{\max }=1.5 \mathrm{dm}^{3} \cdot \mathrm{s}^{-1}$ (see: Fig. 3).

The authors could verify the method of selecting the optimal VFC geometry in the light of the obtained numerical calculations due to swirl parameter $\left(S_{g}\right)$ and its relation to the Euler number $\left(E_{u}\right)$ described earlier (Jarman et al. 2015). Table 1 contains the calculated values of swirl parameter for all three tested VFC geometries and corresponding Euler number values. To calculate the Euler number, through the CFD numerical modelling, average velocities at the outlet from VFC chamber and the pressure difference between its maximum measured value were calculated at the highest point of the chamber (the value of velocity component parallel to the horizontal axis of the outlet orifice is equal to zero) and the value at axial point of the outlet orifice. Pressure height on the surface of VFC chamber circuit is significantly lower than disposable pressure height $(\mathrm{H})$, reaching up to $60 \mathrm{~cm}$ in tests.

This effect is illustrated qualitatively in Fig. 4. The main factor that causes this pressure drop is 
Siuta, T., Mączałowski, A. (2019). Evaluation of vortex flow controls efficiency based on CFD numerical modelling. Acta Sci. Pol., Formatio Circumiectus, 18 (3), 85-95. DOI: http://dx.doi.org/10.15576/ASP.FC/2019.18.3.85

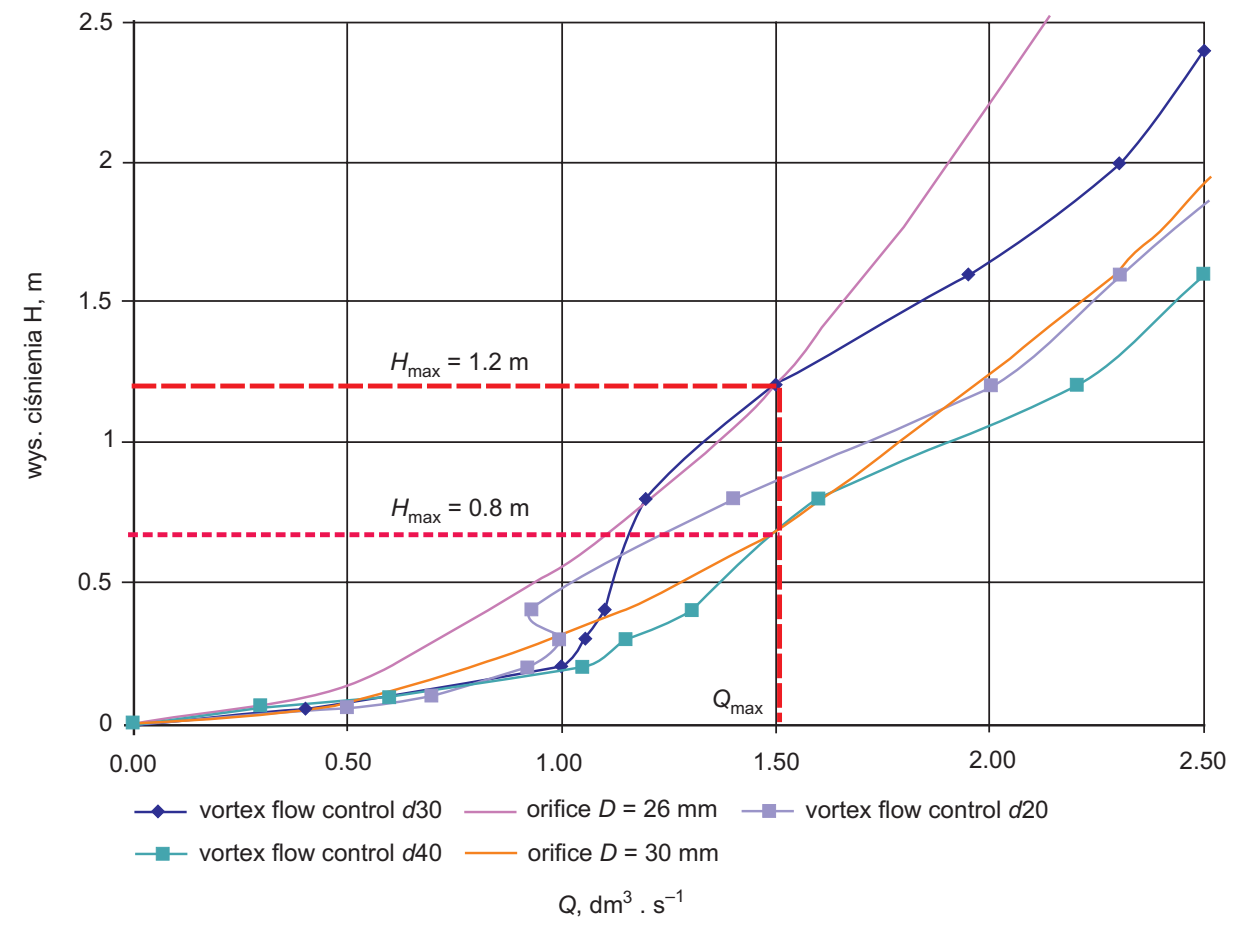

Fig. 3. Characteristics of the tested Vortex flow controls connected with equivalent orifice characteristics (set flow rate $\left.\mathrm{Q}_{\max }=1.5 \mathrm{dm}^{3} \cdot \mathrm{s}^{-1}\right)$

the high value of the angular velocity on chamber plane (reaching up to $2.5 \mathrm{~m} \cdot \mathrm{s}^{-1}$ for $\mathrm{H}=2 \mathrm{~m}$ ). Research (Jarman et al., 2015) proves that the efficiency of VFC is closely related to swirl parameter $\left(S_{g}\right)$ calculated on the basis of its geometric dimensions. If swirl parameter value is greater than 4.7 , the efficiency of impeding high flow rates decreases rapidly (pressure losses decrease with the same disposable pressure height $\mathrm{H})$.

The same research, based on laboratory experiments, has proven that for the mentioned value of parameter $S_{g}$ greater than 4.7 the Euler number (Eu) begins to decrease (or slightly increases). The simulations performed in this study confirm this relationship, i.e. an increase of chamber diameter from $30 \mathrm{~cm}$ to $40 \mathrm{~cm}$, while maintaining the dimensions of the outlet orifice, causes a decrease in the Euler number for the same power conditions (see: Table 1). This is demonstrated in the characteristics course of the tested VFCs. Integral difference between features of the VFC $d 40$ and its equivalent orifice is notably smaller than in the VFC $d 30$ (see: Fig. 3).
Table 1. Values of swirl parameter $\left(S_{g}\right)$ and the Euler number $(\mathrm{Eu})$ calculated for three tested variants of VFCs (designed flow rate $Q_{\max }=1.5 \mathrm{dm}^{3} \cdot \mathrm{s}^{-1}$ ).

\begin{tabular}{ccccc}
\hline & $u_{s r}\left[\mathrm{~m} \cdot \mathrm{s}^{-1}\right]$ & $\Delta \mathrm{p}[\mathrm{Pa}]$ & $S_{g}[-]$ & $\mathrm{Eu}[-]$ \\
\hline $\boldsymbol{d 2 0}$ & 1.32 & 13857 & 3.14 & 15.8 \\
\hline $\boldsymbol{d 3 0}$ & 1.17 & 14000 & 4.71 & 20.4 \\
\hline $\boldsymbol{d 4 0}$ & 1.45 & 13640 & 6.28 & 12.9 \\
\hline
\end{tabular}

\section{ANALYSIS OF TURBULENT FLOW FIELD}

The analysis of velocity field (calculated for disposable pressure head $H=2 \mathrm{~m}$ ) in the axial section of the VFC chamber (see: Fig. 6) indicates that the maximum velocity value (about $2.9 \mathrm{~m} \cdot \mathrm{s}^{-1}$ ) in the variant $d 30$ is concentrated in the narrower axial area of the outlet orifice (compared to the variant $d 20$ ) and with a large gradient decrease in the radial direction - to a value of about $1 \mathrm{~m} \cdot \mathrm{s}^{-1}$ in the axis of the outlet orifice and to a value of about $2.4 \mathrm{~m} / \mathrm{s}$ on the circumference of the VFC chamber. It is interesting that the maximum 
Siuta, T., Mączałowski, A. (2019). Evaluation of vortex flow controls efficiency based on CFD numerical modelling. Acta Sci. Pol., Formatio Circumiectus, 18 (3), 85-95. DOI: http://dx.doi.org/10.15576/ASP.FC/2019.18.3.85
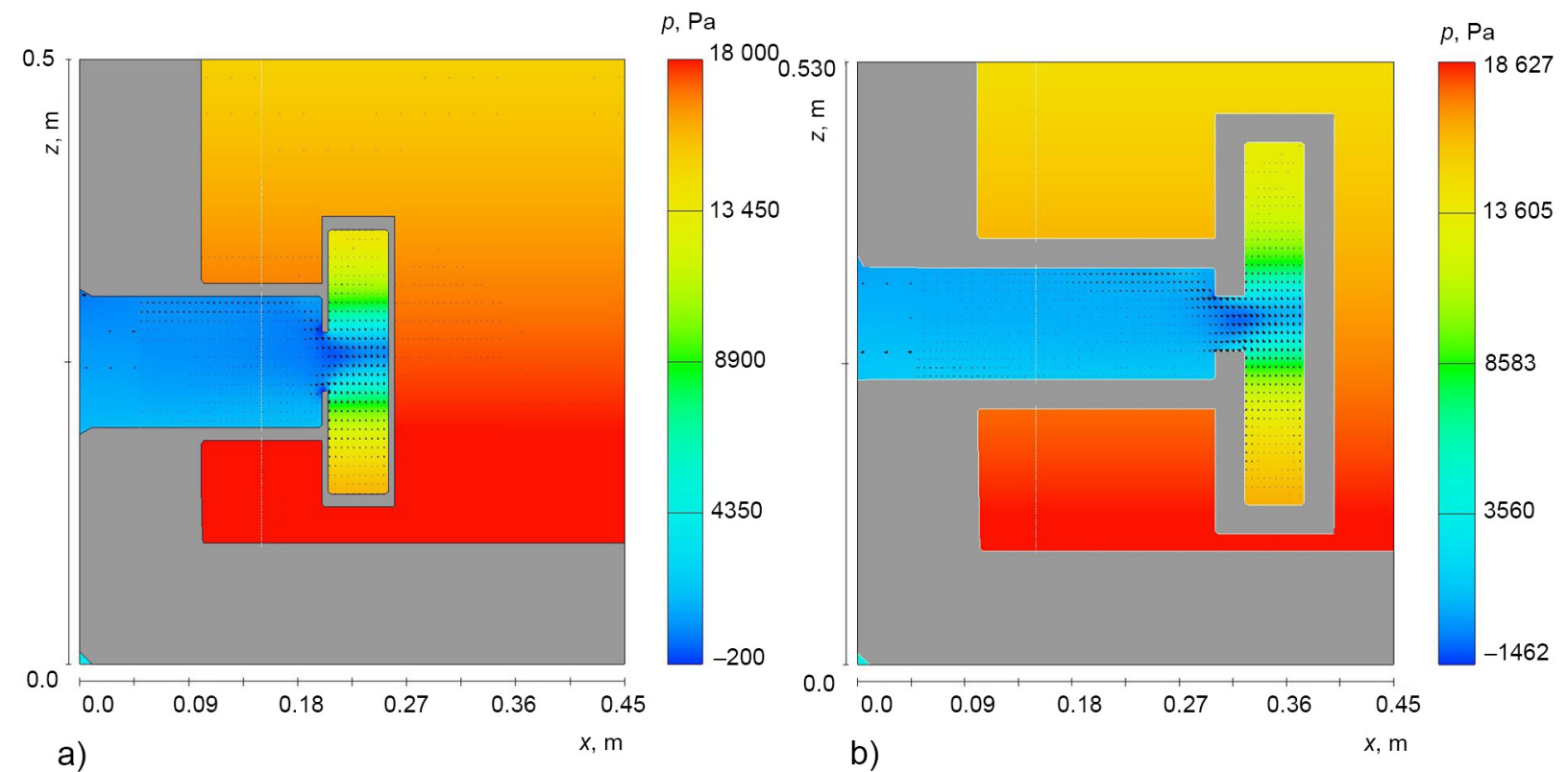

Fig. 4. Distribution of dynamic pressure in a cross-section of the VFC's axis in a vertical plane (a-variant $d 20$, b-variant $d 30$ )
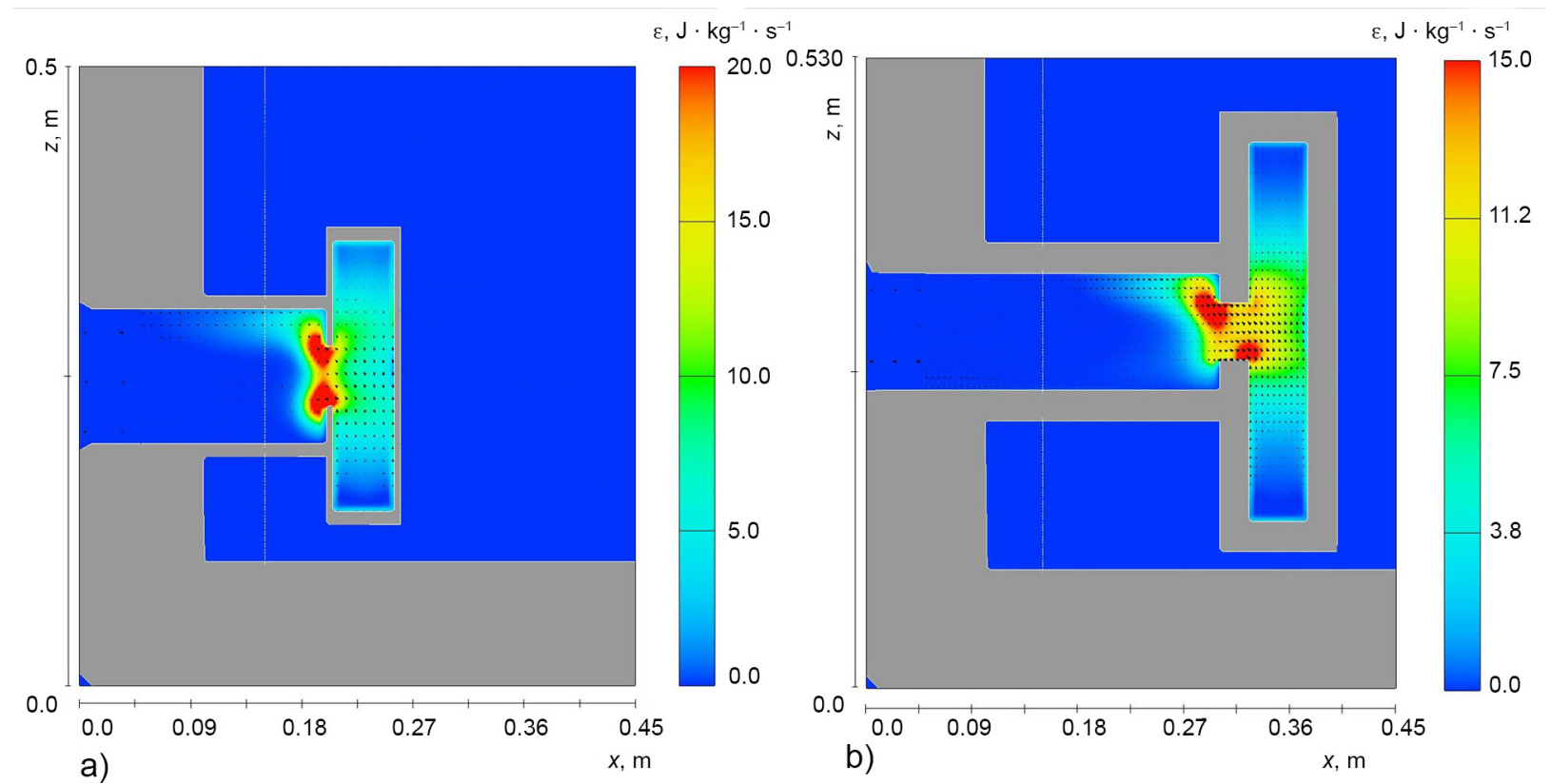

Fig. 5. Distribution of parameter $\varepsilon$ (turbulent energy dissipation rate) in a cross-section of the VFC's axis in a vertical plane (a-variant $d 20$, b-variant $d 30$ ) 
Siuta, T., Mączałowski, A. (2019). Evaluation of vortex flow controls efficiency based on CFD numerical modelling. Acta Sci. Pol., Formatio Circumiectus, 18 (3), 85-95. DOI: http://dx.doi.org/10.15576/ASP.FC/2019.18.3.85
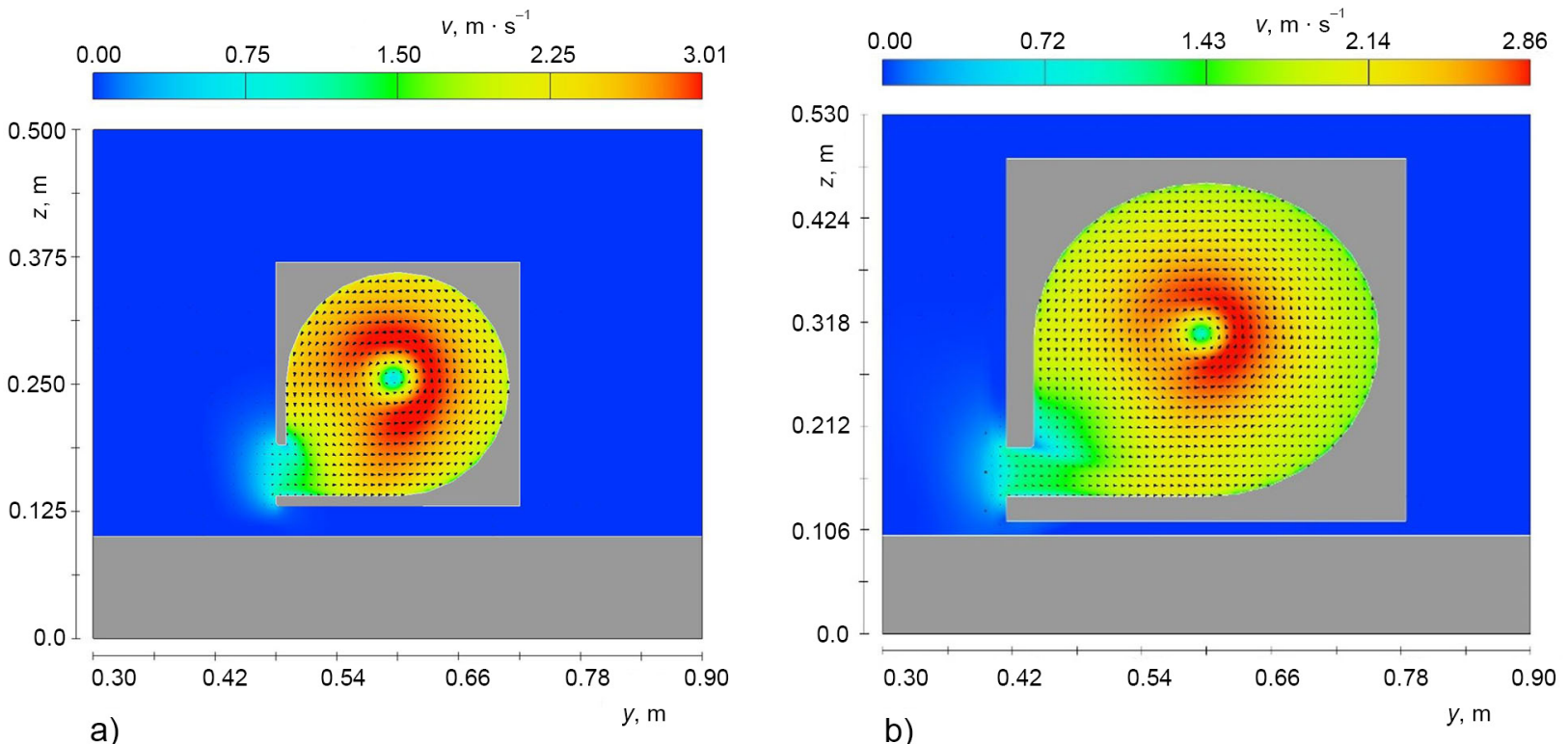

Fig. 6. Velocity distribution in the axial section of the VFC chamber (a-variant $d 20$, b-variant $d 30$ )
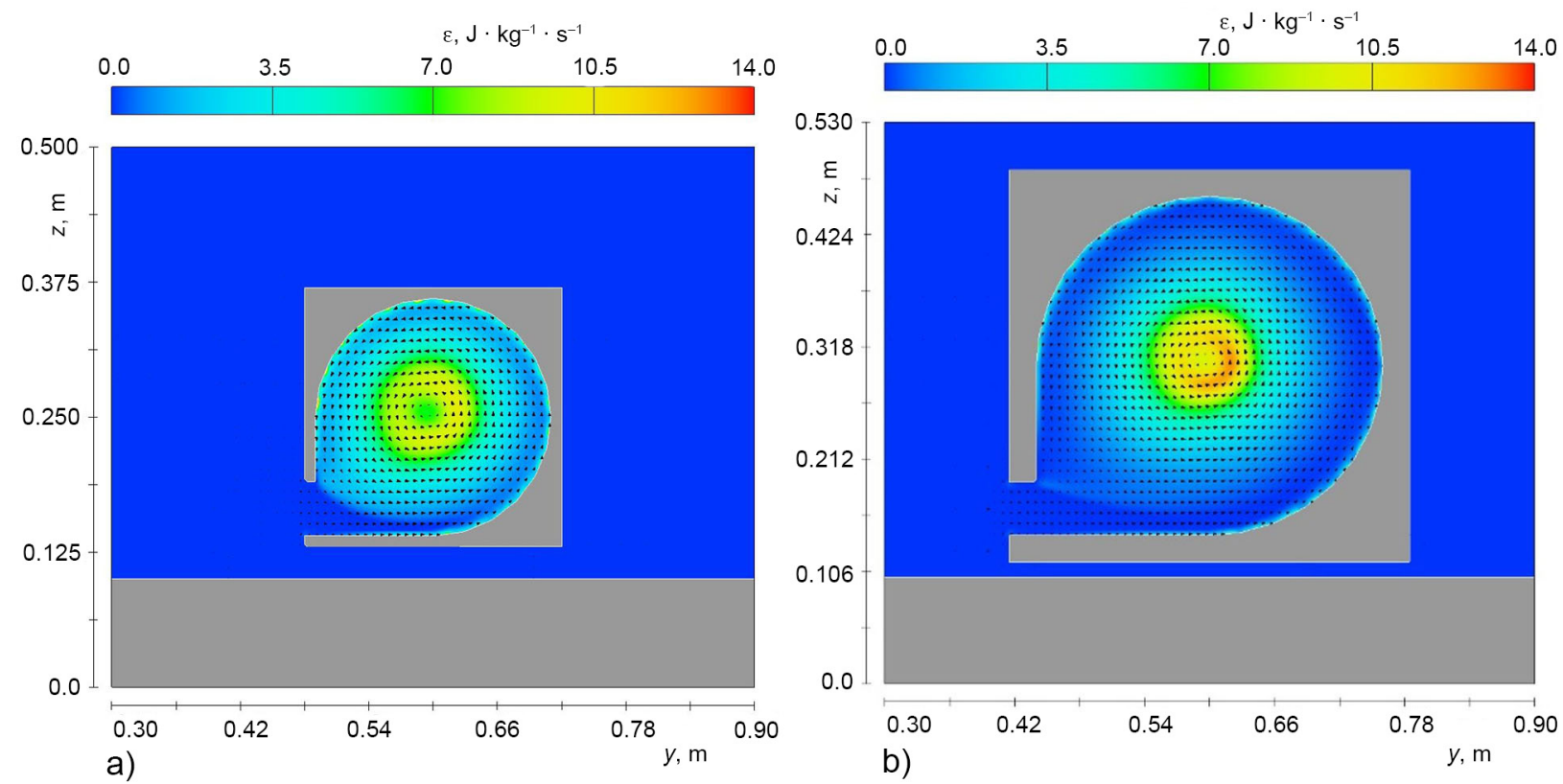

Fig. 7. Distribution of parameter $\varepsilon$ (turbulent energy dissipation rate) - axial cross-section through the VFC chamber (a-variant $d 20$, b-variant $d 30$ ) 
velocity in vortex motion is $1.9 \mathrm{~m} \cdot \mathrm{s}^{-1}$ higher than the average outlet velocity $\left(1 \mathrm{~m} \cdot \mathrm{s}^{-1}\right)$.

A larger velocity gradient translates into slightly higher values of turbulent energy dissipation parameter (reaching $14 \mathrm{~J} \cdot \mathrm{kg} \cdot \mathrm{s}^{-1}$ ) than analogous procedure for the variant $d 20$ (see: Fig. 7). Nevertheless, the area of increased values of parameter $\varepsilon$ (reaching $10 \mathrm{~J} \cdot \mathrm{kg} \cdot \mathrm{s}^{-1}$ ) is larger in the VFC $d 20$. In addition, in the vertical axial cross-section of the outlet stub end the value of $\varepsilon$ arrives at $20 \mathrm{~J} \cdot \mathrm{kg} \cdot \mathrm{s}^{-1}$ (see: Fig. 5). In both, the pressure at the highest point of a chamber can be compared, reaching $13600 \mathrm{~Pa}$, and is $6000 \mathrm{~Pa}$ lower than the disposable pressure.

Another interesting effect is the presence of negative pressure in the chamber outlet area (see: Fig. 4), which reaches up to $-1500 \mathrm{~Pa}$ in the $d 30$ model. This feature of flow can have a significant influence on aeration of outlet streams from the VFC (Faram et al., 2010).

\section{CONCLUSIONS}

The numerical experiment conducted for assessing the effectiveness and representation of the characteristics of vortex flow controls that are designed for outflow rate below $2 \mathrm{dm}^{3} \cdot \mathrm{s}^{-1}$ is an addition to the previous tests for higher outflow rates (Jarman et al., 2015). The analysis shows that the numerical simulation of flow allows mapping the bistable characteristics of vortex flow through VFC devices. The instability range in the tested models lies within a narrow scope of outflow rate values $\left(\Delta Q_{g r}\right.$ does not exceed $\left.0.3 \mathrm{dm}^{3} \cdot \mathrm{s}^{-1}\right)$, and as for the variant VFC $d 30$ the characteristics $H(Q)$ maintain function axioms (the representation is unambiguous). This feature presents new quality, when compared to results of previous studies. To verify the accuracy of calculated characteristics additional laboratory experiments are required. Employing two different (presented in this paper) criteria for optimal VFC geometry may in some cases lead to a different solution. The VFC $d 20$ works optimally by maximizing the capacity reduction after exceeding a certain outflow rate $\left(Q_{g r}\right)$, but as it increases, the efficiency of the VFC drops. The $d 30$ variant, designed for max- imum outflow rate $\left(1.5 \mathrm{dm}^{3} \cdot \mathrm{s}^{-1}\right)$, works optimally by maximizing the capacity for flows below rate values, for which it was designed. In addition, this study has evaluated positively the method of assessing the effectiveness of VFCs on the basis of analysis of calculated values of swirl parameter $\left(S_{g}\right)$. Because this parameter is closely related to basic dimensions of VFC geometry, the aforementioned method also facilitates the optimization of dimensions of "small" VFCs, designed for smaller outflow rate values.

\section{REFERENCES}

Faram, M., Andoh, R., Stephenson, A. (2010). Vortex flow controls: state of the art review and application (from the catchbasin to the dam). Novatech - 7th International Conference on Sustainable Techniques and Strategies for Urban Water Management, Conference paper.

Flow Science, Inc. (2014). FLOW-3D User Manual, Release 11.0.3.

Gupta, A., Lillwey, D. (1984). Swirl Flows. Tunbridge Wells: Abacus Press.

Jarman, D., Butler, D., Tabor, G., Andoh, R. (2015). Modelling of vortex flow controls at high drainage flow rates. Preceding of the institution of Civil Engineers, Engineering and Computational Mechanics, 168, March Issue EM1,17-34.

Kotowski, A., Wojtowicz, P. (2008). Analysis of hydraulic parameters of cylindrical vortex regulators. Environment Protection Engineering, 34, 2, 43-56.

Kubrak, E., Rasińska, M., Grabowski, W. (2015). Charakterystyki przepustowości wirowego regulatora. stożkowego z niezatopionym i zatopionym wylotem. Przegląd Naukowy - Inżynieria i Kształtowanie Środowiska, 69, 224-235.

Parsian, H., Butler, D. (1993). Laboratory investigation into the performance of in-sewer vortex flow regulator. Water and Environment Journal 70(2), 182-189.

Wojtowicz, P., Kotowski, A. (2009). Influence of design parameters on throttling efficiency of cylindrical and conical vortex valves. Journal of Hydraulic Research 470(5), 559-562.

Queguineur, G., Jarman, D., Peterson, E., Tabor, G. (2013). CFD of vortex flow controls at low flow rates. Engineering and Computational Mechanics 166(4), 211-221. 


\section{OCENA EFEKTYWNOŚCI DZIAŁANIA WIROWEGO REGULATORA ODPŁYWU NA PODSTAWIE MODELOWANIA NUMERYCZNEGO TYPU CFD}

\section{ABSTRAKT}

\section{Cel pracy}

Celem pracy było odwzorowanie bi-stabilnej charakterystyki regulatora wirowego jak również wskazanie na optymalne parametry geometrii badanych regulatorów testowych, takich jak: średnica komory, pole otworu wlotowego i wylotowego dla zadanych warunków projektowych. Ponadto, dokonano weryfikacji metody oceniającej zakres efektywnego stosowania regulatorów wirowych na podstawie tzw. parametru wirowego (ang. swirl parameter) w świetle uzyskanych wyników modelowania numerycznego.

\section{Materiał i metody}

W pracy zastosowano modelowanie numeryczne (CFD) odpływu ustalonego przez regulator wirowy dla zadanej wysokości ciśnienia dyspozycyjnego. Serie obliczeniowe przeprowadzono dla trzech wariantów geometrii regulatora. Rozwiązanie numeryczne równań modelu przepływu jednofazowej cieczy nieściśliwej (ang. Reynolds Averaged Navier-Stokes) wraz z domykającymi równaniami modelu turbulencji k-E wykonano w programie komputerowym FLOW 3D.

\section{Wyniki i wnioski}

Uzyskane charakterystyki wydatku regulatora wirowego na podstawie obliczeń numerycznych mają przebieg bi-stabilny (dwugałęziowy oddzielony obszarem niestabilnym) co potwierdzone zostało wcześniej w eksperymentach laboratoryjnych przeprowadzonych przez innych badaczy. Pozytywnie zweryfikowano metodę oceniającą zakres efektywnego działania regulatorów wirowych na podstawie tzw. parametru wirowego (ang. swirl parameter) w świetle uzyskanych wyników modelowania numerycznego co pozwala na optymalne wymiarowanie regulatorów i właściwy ich dobór dla określonych warunków eksploatacji.

Słowa kluczowe: sieć kanalizacyjna, wirowy regulator odpływu, charakterysyka bi-stabilna, parametr wirowy, model numeryczny CFD 